\title{
Os pressupostos filosóficos do cooperativismo educacional no estado de São Paulo
}

Maria Cristiani Gonçalves Silva

Mestranda em Educação pela UNICAMP

César Apareciddo Nunes

Livre Docente em Educação

Vice Chefe do Departamento de Filosofia e História da Educação da FE/UNICAMP Líder do Grupo de Estudos e Pesquisas em Filosofia e Educação PAIDEIA

\section{Resumo}

O presente ensaio pretende analisar o Cooperativismo Educacional no estado de São Paulo, em suas formas institucionais, agora voltados para a organização escolar a partir de 1980. O cooperativismo educacional ocupou um lugar de destaque, com um discurso aparentemente renovador, pois tanto pretendia formar o indivíduo integralmente, afirmando superar a ética da competição pela ética da cooperação, de modo a superar a tradição administrativa hierárquica da escola pública e privada e, apresentar, inclusive, supondo desencadear disposições políticas emancipatórias para todos os envolvidos no processo de ensino aprendizagem. Tendo como referencial teórico Dermeval Saviani, na análise da organização da escola e os pressupostos filosóficos e políticos dessa trajetória, e de Antonio Gramsci, ao relacionar as transformações do trabalho e a questão da educação, pretendemos descrever a expansão do cooperativismo educacional e analisar os seus princípios pedagógicos, organizacionais e políticos.

Palavras-chave: Educação, Educação Cooperativista; cooperativismo.

\begin{abstract}
This essay aims to analyze the Cooperative Education in São Paulo in its institutional forms, now facing the school organization since 1980. The cooperative education occupied a prominent place, with a refreshing speech apparently because both wanted to form the whole person, claiming to overcome the ethics of competition for the ethics of cooperation, in order to overcome the administrative tradition of hierarchical public and private schools, and provide even emancipatory political arrangements for all involved in teaching and learning. The theoretical framework Dermeval Saviani, the analysis of school organization and the philosophical and political assumptions that trajectory, and Antonio Gramsci, to relate changes in work and the issue of education, we intend to describe the expansion of cooperative education and analyze the pedagogical principles , organizational and political..
\end{abstract}

Keywords: Education; Cooperativist Education; cooperativism. 


\section{A práxis do cooperativismo educacional}

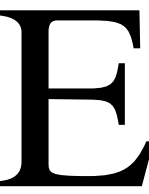

ste texto é resultado do trabalho apresentado no "Seminario Internacional Universidad - Sociedad - Estado 'Reforma Universitaria: Universidades Latinoamericanas y Desarrollo"” que aconteceu na cidade de Montevidéu no Uruguai. Trata-se da pesquisa sobre a Educação Cooperativista no estado de São Paulo. Tal pesquisa localiza-se no grupo de pesquisas, da Faculdade de Educação da Universidade Estadual de Campinas, PAIDÉIA, mais especificamente na linha de pesquisa denominada Ética, Política e Educação, nucleada nas políticas educacionais e seus pressupostos.

O Cooperativismo Educacional como uma forma de organização escolar desenvolveu-se a partir de 1980 a 1990. Tal expansão deu-se, sobretudo, a partir da visibilidade da crise da Educação Pública no modelo tecnicista vigente no período supracitado e a acentuada mercantilização da educação privada, inviabilizando o acesso de parte da classe média: seja pelo alto custo, seja pela forte disputa de vagas.

A criação de Cooperativas Educacionais é um fenômeno recente na história do cooperativismo brasileiro e na história da educação brasileira. A primeira cooperativa educacional surgiu na nos anos de 1980 e ganhou corpo nos anos de 1990. No entanto, os indicadores deste segmento cooperativo revelam índices significativos de crescimento e expansão. Apenas no Estado de São Paulo elas somam mais de 55 escolas e estão presentes em pequenas e grandes cidades.

O cooperativismo educacional ocupou um lugar de destaque nos anos de 1990, com um discurso aparentemente renovador de uma escola que pretendia formar o indivíduo integralmente, superar a ética da competição pela ética da cooperação, organizar-se pedagogicamente com participação plena dos professores como colegiado, superar a tradição administrativa hierárquica da Escola Pública e Privada e, apresentar, inclusive, disposições políticas emancipatórias para todos os envolvidos no processo de ensino 
aprendizagem, desde os gestores, professores, funcionários, alunos, pais e comunidade.

O movimento cooperativo que deu início às modernas cooperativas teve origem no século XVIII e início do século XIX. Ele expressa a reação popular dos setores mais modestos e, ao mesmo tempo, mais numerosos da população frente às situações de injustiça que imperavam na época.

As cooperativas educacionais sejam elas formadas por profissionais em educação, por pais ou até por alunos, estão organizadas dentro do estado de São Paulo pela OCESP - Organização das Cooperativas do Estado de São Paulo, que, por sua vez, está vinculada à OCB - Organização das Cooperativas do Brasil, que se encontra ligada à ACI - Aliança Cooperativa Internacional. Sendo que todas essas entidades estão fundamentadas pelo princípio da "Sociedade dos Probos Pioneiros de Rochdale", quando 28 tecelões, buscando formas de melhorar sua precária situação econômica, fundaram essa primeira cooperativa de consumo, cujos princípios posteriormente constituíram os fundamentos da doutrina cooperativista mundial praticada nos dias atuais.

Neste contexto de problemas que ameaçavam a vida dos setores mais modestos da população, os movimentos sociais explodiram em toda a Europa e assumiram um caráter associativo e classista. Segundo Hobsbawm (1998), por meio do sindicalismo, do cooperativismo e do socialismo, as pessoas aliadas a uma mesma perspectiva ou necessidade desenvolviam atividades conjuntas, produtivas ou não, tendo em vista não somente melhorar suas condições de vida, mas também buscar superar o sistema capitalista causador de tantas mazelas. O cooperativismo propunha a superação pacífica do sistema capitalista, diferente das ideias de Marx, que via na luta de classes o meio de transformação da sociedade.

Porém, Schneider (1981, p. 11) observa que a História se encarregou de revelar o quão utópica foi à proposta de superação da sociedade de classes defendida pelos ideólogos do movimento cooperativista, afirmando 
que as forças propulsoras do sistema capitalista acabaram por incorporar o cooperativismo na própria dinâmica de expansão do capital.

Já do ponto de vista institucional, o ramo cooperativista educacional assumiu uma nova identidade, mas não constituiu um profundo estudo sobre o cooperativismo como expressão de uma determinada forma de pensar o mundo e, por conseguinte, de pensar a organização política, econômica, cultural, social e educacional.

Para tanto nos questionamos: Será o cooperativismo educacional uma possibilidade transformadora ou até revolucionária da educação? Teria o cooperativismo condições políticas de gerar uma nova escola a partir de novas relações entre os envolvidos no processo educacional? Que elementos éticos, estéticos e políticos estariam presentes nessa novidade institucional do cooperativismo nessas dimensões?

Por outro lado: não seria o cooperativismo um reformismo adequado aos interesses de classe, moldados à necessidade de consumo da classe média, reproduzindo os elementos competitivos e autoritários do sistema educacional anterior?

As duas possibilidades não são excludentes, existem escolas com alguma novidade pedagógica institucional e também existem as que produzem um mascaramento da pedagogia cooperativista, referenciada pela pedagogia freiriana e freneitiana.

Em todas as fases históricas da humanidade a cooperação e o trabalho coletivo estiveram presentes na produção da vida humana, seja de forma explicita (maneira de viver em comunidade da sociedade) ou implícita (ações humanas isoladas, independente da forma em que a sociedade está organizada).

A atividade produtiva é sempre social e a sociabilidade, se entendida como um processo humano, não ocorre por instinto, mas por relações intencionalmente construídas. É a necessidade que gera a relação cooperativa entre os seres humanos. Ou seja, quando o ser humano se torna 
consciente de sua incapacidade de resolver individualmente um problema, a tendência é solicitar o auxílio de seu semelhante.

A razão do ato cooperativo está na dificuldade, na dependência, na insuficiência do agir individualizado para a satisfação das necessidades mais ou menos imediatas. Isso não significa abandonar a ideia de que os seres humanos, quando organizados em cooperativas, cultivam uma utopia de que é possível construir uma sociedade em que não haja exploração, injustiças sociais e dominação. Ou seja, a centralidade do ato não está meramente no ideal, mas na necessidade concreta de organização.

De acordo com Marx (1977, p.37). “não é a consciência que determina a vida, mas a vida que determina a consciência”. O cooperativismo é decorrente de uma necessidade humana comum e da consciência de superação conjunta de problemas, com vistas à obtenção de benefícios aos que cooperam.

Para que ocorra o cooperativismo, portanto, são necessárias condições objetivas e subjetivas. A condição objetiva é a situação vivenciada geradora de problemas; a condição subjetiva é a tomada de consciência de que os problemas são comuns e de que, com a união, é possível superá-los, proporcionando vantagens mútuas.

A exemplo da Comunidade de Probos, percebemos que aos poucos os consumidores tomaram consciência de sua força e, começaram a se unir em cooperativas a fim de se opor aos excessos dos produtores e dos intermediários. Desse modo, o movimento cooperativo representou inicialmente um corretivo aos desequilíbrios resultantes do liberalismo. Porém desde o inicio do século $\mathrm{XX}$, as cooperativas passaram a ser utilizadas nas mais diversas e heterogêneas estruturas econômicas, destacando-se principalmente como elemento de progresso das economias subdesenvolvidas.

Muitas cooperativas se organizam buscando trabalhar conceitos que levam a cooperação. Para entendermos um pouco do que pretendem, veremos alguns conceitos: 
Cooperar: É praticar ações em conjunto com outras pessoas, com o mesmo objetivo, na busca de resultados comuns a todos, superando as dificuldades individuais. ${ }^{1}$

Cooperativismo: De acordo com SCHENEIDER ${ }^{2}$ “é uma doutrina, um sistema, um movimento ou, simplesmente, uma atividade que considera as cooperativas como forma ideal de organização da humanidade, baseado na economia solidária, na democracia, na participação, nos direitos e nos deveres iguais para todos, sem discriminação de qualquer natureza, para todos os cooperados”.

As realizações cooperativistas constituem o cooperativismo, portanto cooperação e cooperativismo não são palavras sinônimas. Em nosso trabalho, abordaremos o termo cooperação e empregaremos cooperativismo no sentido de doutrina que tem por objetivo a correção social pelo econômico através de associações de fim predominantemente econômico, ou seja, as cooperativas. E cooperativas no sentido de pessoas organizadas em bases democráticas conforme conceituado por Scheneider.

Durante os mais de 160 anos de existência do movimento cooperativista, o mesmo já foi objeto de estudos sob diversos aspectos, o que possibilitou o aprimoramento do movimento e a sua divulgação no meio acadêmico e leigo, no entanto, devido a sua complexidade, muitos outros aspectos precisam ser explorados para permitir que o arcabouço teórico se aprimore e o movimento possa se fortalecer através da compreensão mais apuradas de seus fenômenos.

Percebemos que ao se difundir em realidades econômico-sociais tão diversas, a doutrina cooperativa tem sofrido algumas modificações por causa das peculiaridades de cada sociedade em que se dá. Todavia, quaisquer que sejam os sistemas econômicos em que se desenvolvem as

\footnotetext{
${ }^{1}$ MICHAELIS: Moderno Dicionário da Língua Portuguesa / São Paulo; Companhia Melhoramentos; 1987.

${ }^{2}$ SCHNEIDER, J. O. Pressupostos da educação cooperativa: a visão de sistematizadores da doutrina do cooperativismo. In: SCHNEIDER, J. O. (Org.). Educação cooperativa e suas práticas. Brasília: SESCOOP. 2003. p.13-58.
} 
cooperativas, determinados princípios doutrinários fundamentais não desapareceram.

A permanência desses princípios vem mostrar não só o rigor e a flexibilidade dessa doutrina, mas também a utilidade de sua aplicação.

Porém, Schneider (1981) critica a disseminação desta visão apologética do sistema cooperativista calcada numa pretensa imutabilidade dos seus princípios Ele entende que são as condições estruturais concretas que determinam a natureza e o funcionamento das cooperativas e não a divulgação de um conjunto de princípios normativos ligados à doutrina cooperativista. Desse modo, a concepção idealista do cooperativismo pouco contribui para o debate em torno do real significado do cooperativismo no contexto da realidade econômica e social do Brasil.

O lugar, o contexto histórico e os interesses em que as cooperativas estão inseridas podem distinguir significativamente as experiências cooperativas. Elas podem assumir características mais ou menos participativas, dependendo dos estágios democráticos de cada país. Rech (1995) observa que nos países como Suécia, Noruega e Israel, onde a democracia deixou de ser mero discurso político para se transformar em benefício e direito, as cooperativas assumem características comunitárioparticipativas, convertendo-se em base organizacional de uma caminhada em busca de uma sociedade mais justa e igualitária.

Os princípios do cooperativismo que orientam a organização de empreendimentos cooperativos não podem estar dissociados dos valores que os sustentam. Vimos que o empreendimento cooperativo possui dupla natureza: uma econômica e a outra social. Estes dois elementos são inseparáveis. Segundo Drimer \& Drimer (1973), nenhuma associação de pessoas é verdadeiramente cooperativa se não cuidar dos aspectos sociais inerentes a ela mesma. Isto quer dizer que as cooperativas não podem descuidar das relações sociais que se estabelecem não apenas entre e os membros da cooperativa, mas também entre a cooperativa e a comunidade mais ampla na qual está inserida. 
Marx (1973) afirma que o cooperativismo não pode ser considerado uma terceira via de organização social, um sistema econômico possível de viabilidade prática, semelhante ao capitalismo ou ao socialismo, mas deve ser entendido como uma atividade que busca, mediante ação coletiva, meios materiais para a valorização das pessoas e não do capital. Sua realização pode se efetivar tanto em uma sociedade capitalista quanto em uma sociedade socialista. É uma prática humana, não econômica ou política.

O cooperativismo é decorrente de uma necessidade humana comum e da consciência de superação conjunta de problemas, com vistas à obtenção de benefícios aos que cooperam.

O processo de tomada de consciência e de organização é educativo, gerando conhecimento e sociabilidade. A atividade educativa, como processo de humanização, mostra a necessidade que temos de nos relacionarmos com as outras pessoas para nos tornarmos humanos. O trabalho do educador, que se educa com sua prática educativa, é perguntar sobre a finalidade do que é humano e construir consciências que possam, livremente, optar e se responsabilizar pelas suas ações.

É neste sentido que nos referimos à pedagogia da práxis cooperativa onde a aprendizagem, assim como o trabalho, está diretamente ligada à formação da consciência humana. As relações sociais decorrentes do trabalho produtivo é que constroem a consciência humana. Nas relações sociais de produção, um ser humano, confrontando-se com outro, na sua interação, percebe sua própria identidade e, com sua presença, contribui na descoberta da identidade do outro.

O modo como o conhecimento é construído e reconstruído baseia-se na práxis, um processo dialético de relação entre teoria e prática, que, gerando novas teorias, propicia novas práticas. É um movimento de constante ação e reflexão, reflexão da ação e ação a partir da reflexão, num trabalho contínuo, dinâmico e ininterrupto.

Para Frigotto (1998, p.58), Marx e Engels dão suporte a esta conclusão, quando afirmam ser a práxis o fundamento do conhecimento, 
posto que o homem só conhece aquilo que é objeto ou produto de sua atividade e porque atua, conhece o que conferirá materialidade ao pensamento. A verdade objetiva, dizem os autores, enquanto concordância entre pensamento e realidade, não é um problema que se possa resolver teoricamente pelo confronto entre diferentes pensamentos; a verdade só se constituirá a partir da relação entre pensamento e realidade, e só assim será práxica.

É assim que surge a necessidade da organização cooperativa, pois a construção da consciência humana é um processo em constante movimento. Mesmo assim, é possível conceber algumas formas diferenciadas no processo, não de maneira estática, mas pela própria dinamicidade de seu desenvolvimento, baseado em contextos históricos e culturais diferenciados da vivência dos sujeitos. O ponto de partida, entretanto, é a prática, as relações entre si e com a natureza, que os seres humanos vivenciam e que passam a ser interiorizadas como representações mentais de uma realidade objetiva e concreta.

Gramsci (1982) compreende que o papel da educação é exatamente esse: organizar a cultura humana. Assim, como as estruturas sociais são criações humanas, a educação, imersa nesse “caldo cultural”, absorve a carga ideológica da tradição e atribui significados a tudo o que herda da sociedade. Podemos afirmar que a educação está fundada no meio social onde ela atua e por isso não é neutra: pode atuar como reprodutora do meio ou contribuir para a sua superação.

Em síntese, as escolas eficazes valorizam o desempenho acadêmico e estabelecem objetivos claros e bem definidos de aprendizagem. Há contínuo acompanhamento do progresso de cada aluno. Possui ambiente ordenado voltado para atividades de ensino/aprendizagem. Contam com a presença de uma liderança administrativa e pedagógica da direção ou coordenação pedagógica. Desenvolvem uma proposta institucional de autonomia de alunos e professores que estimula e que valoriza a cultura do sucesso. Isto requer um senso histórico que seja capaz de incorporar o que funcionou bem 
no passado. A história da escola sempre foi contada como uma história de progresso, vinculada ao projeto moderno e burguês de estabelecer os consensos mínimos. Os estudos que priorizam a relação histórica e institucional entre Estado e Sociedade deixaram de lado um terceiro foco de avaliação: a família-comunidade.

A prática social da educação é geradora de consciências e a formação da cultura humana é o que mantém ou transforma a estrutura da sociedade. Tanto a educação como a cultura são produtos históricos da ação humana e formam o que conhecemos por consciência, o resultado social da relação da humanidade com o ambiente e da relação desse ambiente transformado e reproduzido pelas diversas gerações com as gerações futuras. É a cultura que forma a história humana e essa tradição serve de ponto de partida para a vivência da humanidade em determinado período histórico que, com sua ação diferenciada, pode construir um novo rumo para a história. A história da humanidade é, portanto, a base da educação e da cultura.

O lugar da educação, conforme Gramsci se constitui para além da escola formal, nas diferentes formas de ação coletiva dos seres humanos. No espaço não formal, aquele que apresenta uma intencionalidade, mas não se dá no espaço formal da escola, a educação é uma prática social. A educação, portanto, depende do trabalho social. O cooperativismo e a educação são práticas sociais e, em consequência dessa condição, ambos são espaços de poder na sociedade.

Tanto o cooperativismo como a educação surgiu como produtos sociais decorrentes de necessidades humanas. O cooperativismo é posterior à prática da cooperação, assim como a escola é mais recente que a educação.

Uma nova relação entre escola e sociedade tem que basear-se num respeito pelos direitos das famílias a participarem na ação educativa e num respeito pela autonomia e competência profissional dos professores. A prática educativa é uma atividade existente em todas as sociedades, pois é necessária e torna os indivíduos capazes de atuar no meio social. Estes indivíduos transformam esse meio quando necessário, assim como são por 
ele influenciados, graças aos conhecimentos e experiências culturais desenvolvidos, como valores, crença, modo de agir, técnicas e costumes adquiridos pela prática educativa. As influências educativas são, então, não intencionais (do contexto social e do meio ambiente) e intencionais (quando há intenções e objetivos definidos). A educação escolar se destaca entre as intencionais, principalmente na sociedade atual. Assim quem lida com a educação deve ser capaz de descobrir as relações sociais reais. Visto que a educação escolar coloca ao professor a responsabilidade de permitir aos alunos um desenvolvimento de conhecimentos e habilidades para entendimento crítico dos problemas sociais e das atividades práticas.

Importa lembrar que para Gramsci, discutir a escola numa formação social capitalista é discutir a hegemonia, é pôr a questão do intelectual. O que está posto como pano de fundo no seu pensamento é a construção de uma nova sociedade pelo processo de hegemonização de uma nova cultura, que virá em substituição da cultura burguesa que se fez pelo pensamento liberal.

Há, portanto, uma subordinação ideológica caracterizada pelo senso comum por parte da classe dominante que consegue manter presa a classe dominada. O senso comum produzido, acriticamente, na sociedade burguesa traz em seu bojo relações que apresentam determinadas concepções de mundo a partir do conformismo sócio-político das massas que possuem a crença e a fé nas supostas verdades dogmáticas, preparadas e objetivadas pela classe dominante e por convicções religiosas. E esse seria o papel fundamental das escolas cooperativistas, formarem intelectuais orgânicos comprometidos em darem continuidade ao projeto de emancipação dos trabalhadores.

O intelectual tem por função homogeneizar a concepção do mundo da classe à qual está organicamente ligado, isto é, positivamente, de fazer corresponder esta concepção à função objetiva desta classe numa situação historicamente determinada ou, negativamente, de a tornar autônoma, expulsando desta concepção tudo o que lhe é estranho. O intelectual não é, pois, o reflexo da classe social: ele desempenha um papel positivo para tornar mais homogênea a concepção naturalmente heteróclita 
desta classe. (PIOTTE, 1975, p. 19. In.: MOCHCOVITCH, 1988, p. 18).

O intelectual orgânico enquanto dirigentes e organizadores de um movimento social, no caso o cooperativismo, da organização, ao contrário do senso comum, trabalha pelo bom senso. Trata-se do intelectual orgânico da educação cooperativista que irá produzir a disputa pela hegemonia de construção das matrizes pedagógicas da educação. Seu adversário, representante da classe dominante, é o próprio Estado que não vê com bons olhos algo que surge das bases e tentam cooptá-lo em seus discursos e em suas demandas. O Estado, na concepção de Gramsci, dá legitimidade para uma classe manter a hegemonia sobre outra classe. Assim, na realidade cooperativista, é o Estado que legitima a propriedade privada e sua expansão em cooperativas/empresas determinando com que os cooperados se tornem a classe dominante hegemônica em relação aos desempregados, sem escola de qualidade e assim sucessivamente. A classe hegemônica tem duas funções básicas, a de dominar o grupo social oposto e a de dirigi-lo moral e intelectualmente.

Neste sentido, a educação se apresenta como instrumento de luta conforme nos esclarece Dermerval Saviani apud Mochcovitch (1988, p. 26):

... luta para estabelecer uma nova relação hegemônica que permita constituir um novo bloco histórico sob a direção da classe fundamental dominada da sociedade capitalista - o proletariado". Na tradição marxista-gramsciana existe uma antítese entre sociedade civil e Estado. A sociedade civil se encontra na superestrutura, já o Estado faz parte da estrutura social. Daí a distinção entre o pensamento de Marx e Gramsci. Para Gramsci, a superestrutura apresenta dois momentos: o positivo e o negativo. No momento positivo se encontra a sociedade civil e no momento negativo se encontra a sociedade política. Dessa forma, podemos explorar o conceito de Gramsci acerca do Estado. O Estado para Gramsci é a dialogia entre sociedade política (momento negativo) e a sociedade civil (momento positivo). A sociedade política representa o momento da força, da coerção. A sociedade civil representa a rede complexa de elementos ideológicos. Dessa dialogia é que surge o que Gramsci vai chamar de hegemonia revestida de coerção ou hegemonia coercitiva. Neste sentido, para Gramsci, os 
homens ou são filósofos por natureza ou se encontram num estado de conformismo. Afirma Mochcovitch (1988, p. 41)

Para Gramsci (1984) a filosofia da práxis não poderia ser imediatamente assimilada pelas classes subalternas em uma instituição mecânica com formas atrasadas de educação, qualquer processo de transformação da consciência passa forçosamente pelo senso comum criticado e pelo bom senso elaborado.

Na realidade, a escola é um eixo intimamente articulado com dois outros: a hegemonia e o papel dos intelectuais orgânicos (Gramsci, 1982). Para ele é preciso discutir a questão da escola da mesma maneira que se fará com todas as outras formas de expressão cultural, tendo em vista tentar entender a hegemonia burguesa da formação social capitalista que está instalada e que se pretende romper, desinstalar. Daí que a escola, assim como o partido de quadro, o jornal, que Gramsci chama de "escola de adultos", a revista, enfim, todas as expressões culturais, e hoje temos um turbilhão de "formadores de opinião" através das redes sociais na internet, tudo isso para Gramsci se constituem expressões especialmente políticas; são instâncias através das quais a hegemonia burguesa está consolidada, sedimentada. Urge entendê-las para dissecá-las, para que outra hegemonia se faça e com teor diferente que não de dominação e exploração.

A teoria pedagógica histórico-crítica, sistematizada por Saviani (1991), aponta uma perspectiva de poder de mudança, partindo do pressuposto de que esta teoria é viável, mesmo numa sociedade capitalista: “... uma educação que não seja, necessariamente, reprodutora da situação vigente, e sim adequada aos interesses da maioria, aos interesses daquele grande contingente da sociedade brasileira, explorado pela classe dominante..." (p.94).

Embora consciente da determinação exercida pela sociedade sobre a educação, fato que a torna crítica, acredita que a educação também interfere sobre a sociedade, podendo contribuir para a sua própria transformação. 
As teorias utilizadas integram-se, apontando caminhos para a construção emancipatória da educação, dentro da perspectiva materialista dialética, o que entendemos ser de extrema necessidade para a prática da verdadeira educação cooperativista.

Em síntese, entendemos que o cooperativismo é uma novidade filosófica, econômica, cultural e social. Como expusemos, cooperar significa agir em equipe, trabalhar coletivamente, atuar em conjunto, produzir e viver solidariamente. Desse modo, a novidade institucional do cooperativismo se apresenta nessa direção, de mudar radicalmente as estruturas de nossas formas de produzir, viver, organizar o trabalho e a nossa própria sociedade.

Entendemos que as escolas cooperativistas assumem o cooperativismo como “princípio pedagógico e administrativo” das escolas e da própria educação. Trata-se de uma nova pedagogia, de um jeito novo de organizar a educação e a escola, sua natureza institucional, currículo, avaliação, seu diaa-dia, enfim. Esse artigo representa a proposta de uma educação cooperativista, de uma escola cooperativista e de um novo horizonte para a educação brasileira.

As perspectivas para o cooperativismo estão imbricadas na marcha dos sujeitos e vanguardas sociais emancipatórias. O Cooperativismo é chamado hoje a superar as práticas históricas de dependência do Estado ou ainda a objetiva intencionalidade de reproduzir a matriz estreita do capitalismo atual, tomado aqui como sistema de produção e não como conceito ideológico. A cooperação como "ethos" da produção e organização da ação coletiva e produtiva deve ter a coragem de mudar a gestão, a convivência, a produção, a distribuição de seus produtos. O paradigma da sustentabilidade, humana e ambiental, deve ser seu parceiro e inspiração. 


\section{Referências Bibliográficas}

BIANCHI, Álvaro. O Laboratório de Gramsci: filosofia, história e politica. São Paulo: Alameda, 2008.

BURLATSKI, F. Fundamentos da Filosofia Marxista e Leninista. Parte II, Cap.I e V. Tradução de K. Asryants. Moscou(URSS):.Edições Progresso. 1987.

CHAUÍ, Marilena. Cultura e Democracia: o discurso competente e outras falas. São Paulo, Editora Moderna. 1981.

DRIMER, Alicia Keplan \& DRIMER, Bernardo. Las Cooperativas: Fundamentos História - Doctrina. Buenos Aires: INTERCOOP Editora Cooperativa Ltda, 1973.

FREIRE, Paulo. Pedagogia da Autonomia. Editora Paz e Terra. São Paulo. 2006. . Pedagogia do oprimido. 32ª ed. Rio de Janeiro: Paz e Terra, 2002b.

GADOTTI, Moacir. História das idéias pedagógicas. 8ª ed. São Paulo: Ática, 2001.

GAMBOA, Silvio Anázar Sanches. A Dialética na Pesquisa em Educaşão: elementos de contexto. Cap. 7. In: FAZENDA, Ivani (org.). Metodologia da Pesquisa Educacional. São Paulo: Cortez (Biblioteca da Educação. Série 1a Escola; v.11), 1989.

GRAMSCI, Antonio. Concepção dialética da história. $5^{\mathrm{a}}$ ed., Rio de Janeiro, Civilização Brasileira, 1984.

Os intelectuais e a organização da cultura. (tradução de Carlos Nelson Coutinho). $4^{a}$ ed. Rio de Janeiro: Civilização Brasileira. 1982.

Poder, Política e Partido. (tradução Gilberto D'Angelo Braz). 2. ${ }^{a}$ ed.

São Paulo: Editora Brasiliense. 1992.

HOBSBAWM, E. J. Marx, Engels e o socialismo pré-marxiano. In: História do Marxismo. Rio de Janeiro: Paz e Terra. 1980.

JESUS, Antonio Tavares de. O Pensamento e Prática Escolar de Gramsci. 2. ${ }^{a}$ ed. Campinas, SP: Autores e Associados, 2005.

MARX, Karl e ENGELS, Friderich. Crítica da educação e do ensino. Lisboa, Moraes Editores, 1978, p. 224.

O Manifesto Comunista. São Paulo: Paz e Terra. 2005.

A Ideologia Alemã: I - Feuerbach. São Paulo, Hucitec, 1984 e 1996. 
MARX, Karl. Cooperativismo e socialismo. Tradução e prefácio: Rui Namorado. Coimbra: Centelha, 1973.

MÉSZÁROS, István. A educação para além do capital. São Paulo, Boitempo Editorial. 2005.

NUNES, César A.. Educar para a emancipação. Florianópolis, SC: Sophos. 2003.

Educação, Pedagogia e Sociedade: matrizes politicas e estigmas culturais da instituição escolar no Brasil. Cap. 1. In ROMÃO, Lucilia M. S. (org). Leitura, História e Educação: um diálogo possivel. Ribeirão Preto/SP: Alphabeto Editora. 2006.

OLIVEIRA, Irani Sebastião. Educaşão e Cooperativismo: Administração, pedagogia e politica na cooperativa de ensino.1994. Dissertação (Mestrado em Educação) Programa de Mestrados em educação Universidade Estadual Paulista, Marília, 1994.

RECH, Daniel. Cooperativas: uma alternativa de organização popular. Rio de Janeiro: Fase, 1995.

SAVIANI, Dermeval. Escola e democracia. Ed. Comemorativa. Campinas, SP: Autores Associados. 2008a.

Pedagogia histórico-crítica: primeiras aproximações. v-40; São Paulo: Autores Associados, 1991.

SOARES, Antônio Jorge. DIALÉTICA, EDUCAÇÃO E POLÍTICA: uma releitura de Platão. São Paulo: Cortez. 1999. 